\title{
Psikolojik Sağlamlık ve Okul İkliminin Ortaokul Öğrencilerinin Yaşam Doyumunu Yordama Gücü ${ }^{1}$
}

\section{The Predictive Value of Resilience and School Climate in Life Satisfaction among Middle School Students}

\author{
Aslı UZ BAȘ $^{2} \quad$ İrfan YURDABAKAN ${ }^{3}$

Başvuru Tarihi: 20.10.2016 Yayına Kabul Tarihi: 29.12.2016 $\quad$ DOI: 10.21764/efd.32175

Özet: Araştırmanın amacı, ortaokul öğrencilerinde psikolojik sağlamlık ve okul ikliminin yaşam doyumunu yordama gücünü tespit etmektir. Araştırmanın çalışma grubunu, İzmir'de iki farklı devlet ortaokulunda öğrenim gören ve yaşları 10 ile 15 arasında değişen 127 'si k1z, 127'si erkek toplam 254 öğrenci oluşturmaktadır. Veriler, Çok Boyutlu Öğrenci Yaşam Doyumu (kısa formu), Çocuk ve Genç Psikolojik Sağlamlık ve Ortaokul Öğrencileri İçin Okul İklimi ölçekleriyle toplanmıştır. Verilerin çözümlenmesi betimsel istatistikler, Pearson korelasyon analizi ve stepwise regrasyon analizi ile yapılmıştır. Araştırmadan elde edilen bulgular, psikolojik sağlamlık ve okul ikliminin öğrencilerin yaşam doyumlarının anlamlı birer yordayıcısı olduğunu göstermiştir.

Anahtar Sözcükler: Psikolojik Sağlamlık, Okul İklimi, Yaşam Doyumu, Yordama
Abstract: The aim of the syudy is to investigate the predictive value of resilience and school climate in life satisfaction among middle school students. The participants of this study includes a total of 254 middle school students (127 girls and 127 boys) aged 10 to 15 years which attend to different public schools in İzmir. The Brief Multidimensional Students' Life Satisfaction Scale, The Child and Youth Resilience Scale and middle school student version of School Climate Survey were used to gather data. Descriptive statistics, Pearson correlation analysis and stepwise regression analysis were used to analyze the data. The results revealed that resilience and school climate significantly and positively predicted life satisfaction scores in middle school students.

Keywords: Resilience, School Climate, Life Satisfaction, Prediction

\section{Giriş}

Yaşam doyumu, öznel iyi oluşun önemli göstergelerinden biri olup, bireyin genel olarak kendi yaşam kalitesine ilişkin subjektif değerlendirmelerine işaret etmektedir (Diener and Diener, 1995). Yaşam doyumu, pozitif psikolojinin önemli bir kavramıdır. Yaşam doyumuna ilişkin ölçümler, bireyin hem iyi-oluşuna hem de psikopatolojisine dair önemli bir gösterge olmaktadır (Gilman and Huebner, 2003). Greenspoon ve Saklofske (2000), yaşam doyumunun çocuklarda pozitif psikolojik iyi-oluşun en önemli göstergesi olduğunu iddia etmektedir. Yaşam doyumu, çocuk ve ergenlerde stresli yaşam olaylarına ve patolojinin gelişimine karşı koruyucu bir işleve sahip olması bakımından yaşam doyumunu arttırmaya yönelik çalışmalara gereksinim vardır.

\footnotetext{
${ }^{1}$ Çalışma 1. Avrasya Pozitif Psikoloji (28-30 Nisan 2016/İstanbul) kongresinde sözel bildiri olarak sunulmuştur.

${ }^{2}$ Doç. Dr. DEÜ, Buca Eğitim Fakültesi, EBB, RPD ABD. İzmir, asliuzbas@gmail.com

${ }^{3}$ Doç. Dr. DEÜ, Buca Eğitim Fakültesi, EBB, EÖD ABD. İzmir, irfan.ybakan@gmail.com
} 
Yaşam doyumunun yaşamın farklı alanlarındaki olumlu ve olumsuz yapılarla ilişkili olduğu görülmektedir. Proctor, Linley ve Maltby (2009), gençlerde yaşam doyumu üzerine 141 amprik çalışmayı içeren kapsamlı derleme çalışmalarında, yaşam doyumunun, çeşitli duygusal, sosyal ve davranışsal yapılarla ilişkili olduğunu; aynı zamanda psikolojik duygulanımın ve depresyon ve fiziksel sağlığın önemli bir yordayıcısı olduğunu bildirmektedir. Bunun yanında gençlerde yüksek düzeyde yaşam doyumunun sağlıklı bir yaşam stili, daha iyi fiziksel sağlık, sportif ve sosyal aktivitelere katılımın bir sonucu olduğu; tersi şekilde madde kullanımı, şiddet ve saldırganlık gibi riskli davranışlara katılmamanın, daha düşük düzeydeki yaşam doyumu ile bağlantılı olduğu bildirilmektedir.

Yaşam doyumu araştırmalarının alanyazında ağırlıklı olarak yetişkinlerden oluşan katılımcılarla yürütüldüğü ve yaşam doyumunun genel bir yapı olarak ele alındığı görülmektedir. Çocuk ve ergenlerde yaşam doyumu üzerine araştırmalar 1980'lerin sonlarında başlamıştır (Adelman, Taylor, \& Nelson, 1989). Farklı ölçme araçlarının geliştirilmesine paralel olarak, çocuk ve ergenlerde yaşam doyumu araştırmalarında son yıllarda bir artış olduğu görülmektedir (Çivitçi, 2009). Bu araştırmalarda, yaşam doyumu, yetişkinlerden farklı olarak çok boyutlu bir yapı olarak ele alınmaktadır. Çocuk ve ergenlerin yaşam doyumlarını değerlendirmek üzere yaygın olarak kullanılan Çok Boyutlu Öğrenci Yaşam Doyumu Ölçeği ve Çok Boyutlu Öğrenci Yaşam Doyumu Ölçeği-Kısa Formu çok boyutlu bir yapıya sahiptir (Huebner, 1994; Seligson, Huebner, and Valois, 2003). Yaşam doyumunun alt alanları, okul, aile, arkadaşlar, yaşanılan çevre ve öğrencinin kendisini içermektedir.

$\mathrm{Bu}$ araştırma ortaokul öğrencilerinin yaşam doyumu üzerine odaklanmaktadır. Ortaokul eğitim kademesi, gelişimsel dönemler çerçevesinde değerlendirildiğinde ön ergenlik dönemine karşıllk gelmektedir. Bu dönem fiziksel, duygusal ve kişilerarası ilişkiler alanında hızlı gelişmelerle karakterizedir. $\mathrm{Bu}$ geçiş dönemi akademik performansta, benlik imajında, algılanan sosyal destek ve sosyal ilişkilerde gerilemelere yol açabilmektedir (Kuperminc, Leadbeater ve Blatt, 2001). Ortaokul döneminde ergenler ebeveynlerinden özerkleşmeye, akranlar ve diğer yetişkinlerle yakın ilişkiler kurma gereksinimi duymaya başlamaktadırlar (Eccles ve ark., 1993). Ortaokul döneminde yaşanan olumsuz psikolojik değişimler ergenlerin gereksinimleri ile okul çevrelerinin onlara sağladıkları ortamların uyuşmamasından kaynaklanabilmektedir (Seidman ve ark., 1994). Nitekim ortaokul öğrencilerinin normatif bir gelişimsel süreçten geçerken deneyimledikleri değişimlerin üstesinden gelme yetenekleri hem onların bireysel farklılıkları hem de içindeki bulundukları okul ortamının özelliklerine bağlı olmaktadır (Alvidrez ve Weinstein, 1993). Bu noktadan hareketle, bu çalışmada ortaokul öğrencilerinin bireysel özellikleri bağlamında psikolojik sağlamlıkları, okul ortamı ile ilgili çevresel özellikler bağlamında ise okul iklimine yönelik algıları yaşam doyumunun potansiyel yordayıcıları olarak çalışmaya dahil edilmiştir.

Psikolojik sağlamlık, olumsuz yaşantılar, güç durumlar ve zorluklarla karşılaştıktan sonra bu zorlukların üstesinden gelme ya da kendini toparlama yeteneğidir (Johnson, 2008). Psikolojik sağlamlık sosyal ve duygusal iyi-oluşu geliştirmeye yardımcı olan bir faktördür. Olumsuz sonuçlar üretme potansiyeli olan bir risk durumuyla karşı karşıya gelindiğinde, psikolojik sağlamlık fiziksel ve ruhsal sağlık, iyi-olma duygusu, 
akademik gelişme ve topluma katılım gibi işlevsel sonuçları ortaya çıarmaktadır. İşlevsel sonuçların neler olduğu sosyo-kültürel yaşama, tarihsel döneme ve çocukların gelişimsel dönemlerine göre değişebilmektedir. Bu yönüyle psikolojik sağlamlık karmaşık ve dinamik bir yapıdır (Theron, 2016).

Psikolojik sağlamlık, bireysel ve çevresel risk faktörleri ve koruyucu faktörlere bağlı olarak gelişen bir yapı olarak kabul edilmektedir. Erken çocukluk dönemindeki olumsuz deneyimler, yoksulluk ve aile-içi şiddet gibi unsurlar psikolojik sağlamlığın gelişimi bakımından risk faktörleri arasında değerlendirilmektedir (Karaırmak, 2006). Koruyucu faktörler çocuğun kendisi, ailesi ya da içinde bulunduğu toplumdan kaynağını alabilmektedir (Werner, 1995). Yüksek düzeyde sosyal beceriler, problem çözme becerileri ve öz-yeterlik psikolojik sağlamlığa katkıda bulunan bireysel özelliklerden bazıları iken, olumlu aile ve akran ilişkileri ise psikolojik sağlamlığı destekleyen çevresel özellikler arasında yer almaktadır.

Çocuk ve ergenlerde yaşam doyumunun psikolojik sağlamlıkla ilişkilerini ele alan araştırmalar görece az sayıda olmakla birlikte çalışmaların sonuçları benzerlikler göstermektedir. Baltacı ve Karataş (2015) ortaokul öğrencilerinde sosyal destek ve yaşam doyumunun psikolojik sağlamlığın anlamlı birer yordayıcısı olduğunu bulmuşlarıdır. Youngblom, Houlihan ve Nolan (2014), Belize'de lise öğrencileri ile yaptıkları çalışmada psikolojik sağlamlığın kaynaklar alt boyutunun yaşam doyumunun anlamlı bir yordayıcısı olduğunu bulmuştur. Abolghasemi ve Varaniyab (2010), İran'da 14-17 yaşlarındaki öğrencilerle yaptıkları çalışmalarında psikolojik sağlamlığın, öğrencilerde yaşam doyumunun anlamlı bir yordayıcısı olduğunu bulmuştur.

Mevcut çalışma kapsamında ortaokul öğrencilerinin yaşam doyumu düzeylerinin potansiyel yordayıcısı olarak ele alınan diğer değişken ise okul iklimidir. Okul iklimi, okul yaşamının niteliği ve özelliklerine işaret etmektedir. Okul iklimi, okul yaşamını paylaşan kişilerin yaşantıları üzerine temellenmekte ve normlar, amaçlar, değerler, kişilerarası ilişkiler, öğretme ve öğrenme uygulamaları ve örgütsel yapıları yansıtmaktadır (Cohen ve ark., 2009). Okul iklimi, çok boyutlu bir yapı olup, okul binasının fiziksel yapısı ile öğretmenler ve öğrenciler arasındaki etkileşimler gibi farklı özellikleri içermektedir (Marshall, 2004). Olumlu bir okul iklimi, hem çocuk ve ergenlerin sağlıklı gelişimlerini, hem de demokratik bir toplumda yaşamdan doyum sağlamak ve üretici öğrenme için gereksinim duyulan öğrenme süreçlerini desteklemektedir. $\mathrm{Bu}$ ortam, insanların sosyal, duygusal ve fiziksel olarak kendilerini güvende hissetmelerini destekleyen normlar, değerler ve beklentilerini içermektedir (Cohen ve ark., 2009).

Okul iklimi ve yaşam doyumu arasındaki ilişkileri ele alan çalışmalar oldukça sınırlı olmakla beraber, araştırma sonuçları iki değişken arasındaki anlamlı ilişkileri bildirmektedir (Bugay ve ark., 2015). Bunun yanında, okul ikliminin öğrencilerin benlik saygısı üzerinde etkili olduğu, öğrencilerin psikiyatrik problemleri ve benlik kavramları ile ilişkili olduğu önceki araştırmalarla gösterilmiştir (Cohen ve ark., 2009). Bunun yanında Telef (2014), ilkokul ve ortaokul öğrencileri ile yaptığı çalışmasında okul doyumunun yaşam doyumu ile ilişkili olduğunu bildirmiştir. 
$\mathrm{Bu}$ çalışmanın amacı ortaokul öğrencilerinin psikolojik sağlamlık ve okul iklimi algılarının onların yaşam doyumu düzeylerinin anlamlı yordayıcıları olup olmadığını incelemektir. Bu çalışma kapsamında, öğrencilerin yaşam doyumu düzeyleri Çok Boyutlu Öğrenci Yaşam Doyumu Ölçeği-Kısa Formu’nun toplam puanı üzerinden genel yaşam düzeylerini değerlendirecek şekilde ele alınmıştır. Araştırmadan elde edilecek bulguların özellikle okul ortamlarında öğrencilerin psikolojik iyi-oluşlarını geliştirmeye yönelik çalışmalara 1şık tutması beklenmektedir. Yaşam doyumunun psikolojik iyi-oluşun en önemli göstergelerinden birisi olması dikkate alındığında, yaşam doyumunu etkileyen faktörlerin açıklığa kavuşturulması, önleyici ve geliştirici çalışmaların hazırlanması sürecinde araştırmacı ve uygulamacılara yön verebilir.

\section{Yöntem}

\section{Çalışma Grubu}

Araştırmanın katılımcıları İzmir metropol ilçelerinde bulunan iki farklı devlet ortaokulunda öğrenim gören 127'si kız, 127'si erkek toplam 254 öğrencidir. Öğrencilerin 82'si 5. sınıf, 51'i 6. sinıf, 62'si 7. sınıf ve 59'u 8. sınıf öğrencisidir. Öğrencilerin yaşları 10 ile 15 arasında değişmektedir.

Veri Toplama Araçları

Çok Boyutlu Öğrenci Yaşam Doyumu Ölçeği Kısa Formu (Siyez ve Kaya, 2008): Ölçek, Seligson ve arkadaşları (2003) tarafından beş alandaki (aile, okul, arkadaşlar, kendisi, çevresi) yaşam doyumunu değerlendirmek amacıyla geliştirilmiştir. 7'li Likert türü bir ölçektir. Türkçe'ye uyarlama çalışması Siyez ve Kaya (2008) tarafından yapılmıştır. Ölçeğin Türkçe formunun test-tekrar güvenirlik katsayısı 0,82, alfa içtutarl111k katsayısı 0,89 olarak bulunmuştur.

Çocuk ve Genç Psikolojik Sağlamlık Ölçeği (Arslan, 2015): Liebenberg, Ungar ve Van de Vijver (2012) tarafından sosyo-ekolojik bir bakış açısıyla geliştirilen ölçek 28 maddeyi içermektedir. Ölçeğin kısa form çalışması ise Liebenberg, Ungar ve LeBlanc (2013) tarafından yapılmış ve 12 maddelik form geliştirilmiştir. Ölçeğin Türkçeye uyarlama çalışması ise Arslan (2015) tarafından yapılmıştır. Beşli likert yapıda olup "Beni tamamen tanımlıyor (5)" ile "Hiç tanımlamıyor (1)" arasında derecelendirilmektedir. Ölçeğin Türkçe formunun iç tutarlılık katsayısı 0,91 olarak bulunmuştur.

Ortaokul Öğrencileri İçin Okul İklimi Ölçeği (Atik ve Yerin Güneri, 2016): Emmons ve ark. tarafından (2002) okuldaki genel iklimi ve öğrenciler ile okul personeli arasındaki ilişkilerin niteliğini değerlendirmek amacıyla geliştirilmiş olan ölçek Türkçeye Atik ve Yerin Güneri (2016) tarafından uyarlanmıştır. Ölçeğin orijinal formu 37 madde ve altı alt boyuttan oluşmaktadır. Türkçe formunda ise 36 madde bulunmaktadır. Bir madde Türk kültürüne uygun olmaması nedeniyle çıkarılmıştır. Ölçek maddeleri üçlü bir derecelendirme (3=Katılıyorum, 2=Emin değilim, 1=Katılmıyorum) üzerinden yanıtlanmaktadır. Ölçeğin alt boyutları, (1) Adalet; Düzen ve Disiplin; (2) Veli Katılımı; (3) Kaynakların Paylaşımı; (4) Öğrencilerin Kişilerarası İlişkileri ve (5) Öğrenci-Öğretmen İlişkileridir. Ölçeğin Türkçe formunun iç tutarlılığı iki ayrı çalışma 
grubuyla değerlendirilmiş ve ölçeğin toplamı için alfa katsayısı sırasıyla 0,90 ve 0,89 olarak bulunmuştur. Ölçeğin test-tekrar güvenirlik katsayısı ise 0,67 olarak bulunmuştur.

Veri Toplama Süreci ve Analizi

Araştırmaya ait veriler 2015-2016 öğretim y1lının Bahar döneminde toplanmıştır. Uygulama ile ilgili okul yönetimlerinden gerekli izinler alınmış ve öğrenciler araştırmanın amaç ve kapsamı ile veri toplama süreci hakkında bilgilendirilmişlerdir. Ölçme araçları öğrencilere sınıf ortamında, okul psikolojik danışmanının gözetiminde uygulanmıştır. Uygulama yaklaşık olarak 30 dakika sürmüştür. Verilerin analizinde betimsel istatistiklerin yanı sıra, Pearson Çarpım Momentler korelasyon ve regresyon analizinden (stepwise yöntemi) yararlanılmıştır.

\section{Bulgular}

Ortaokul öğrencilerinin Çok Boyutlu Öğrenci Yaşam Doyumu Ölçeği-Kısa Formu, Çocuk ve Genç Psikolojik Sağlamlık Ölçeği ve Ortaokul Öğrencileri için Okul İklimi Ölçeği’nden almış oldukları puanların ortalama ve standart sapmaları, minimum ve maksimum puanları ile çarpıklık ve basıklık katsayıları Tablo 1 'de verilmiştir.

Tablo1. Ölçek ve Alt Ölçek puanlarıyla İlgili Betimsel İstatistikler (N=254)

\begin{tabular}{lcccccc}
\hline Ölçek ve Alt Ölçekler & $\boldsymbol{X}$ & $\boldsymbol{S}_{\boldsymbol{x}}$ & En düşük & En yüksek & Çarpıklık & Basıklık \\
\hline Yaşam Doyumu-Toplam & 33,99 & 6,44 & 9 & 42 & 1,07 & 1,08 \\
Psikolojik Sağlamlık-Toplam & 51,88 & 5,99 & 33 & 60 & $-0,95$ & 0,52 \\
Okul İklimi - Toplam & 80,77 & 10,13 & 46 & 102 & $-0,45$ & 0,29 \\
Adalet & 9,89 & 1,97 & 4 & 12 & $-0,59$ & $-0,69$ \\
Düzen ve Disiplin & 12,89 & 2,66 & 7 & 19 & 0,05 & $-0,50$ \\
Veli Katılımı & 10,85 & 2,37 & 5 & 15 & $-0,30$ & $-0,45$ \\
Kaynakların Paylaşımı & 8,50 & 2,13 & 4 & 12 & $-0,90$ & $-0,78$ \\
Öğrencilerin Kişilerarası İlişk. & 14,65 & 3,20 & 7 & 21 & $-0,07$ & $-0,59$ \\
Öğretmen-Öğrenci İlişkileri & 23,99 & 3,37 & 9 & 27 & $-1,27$ & 3,49 \\
\hline
\end{tabular}

Tablo 1'de verilen çarpıklık katsayıları incelendiğinde toplam ölçek puanlarıyla ilgili değerlerin 1,07 ile 0,45; basıklık değerlerinin ise 1,08 ile 0,29 arasında değiştiği görülmektedir. Çokluk, Şekercioğlu ve Büyüköztürk (2012), söz konusu değerlerin \pm 1 sınırlarına yakın çıkmasının dağılımların normalden aşırı sapma göstermeyeceğini ifade etmişlerdir. Eldeki üç ölçeğin toplam puanlarıyla ilgili çarpıklık ve basıklık katsayılarının \pm 1 sınırlarına yakın çıkmasının puanların normal dağıldığı şeklinde yorumlanması mümkündür.

Çalışmanın bir sonraki aşamasında ortaokul öğrencilerinin yaşam doyumu, psikolojik sağlamlık ve okul iklimi toplam ve alt ölçek puanları arasındaki ilişkiler Pearson Çarpım Momentler korelasyonu ile incelenmiş ve sonuçlar Tablo 2'de verilmiştir. 
Tablo 2. Yaşam Doyumu, Psikolojik Să̆lamlık ve Okul İklimi Arasındaki İlişkiler

\begin{tabular}{|c|c|c|c|c|c|c|c|c|}
\hline & PS & Oİ-T & A & DD & VK & KP & ÖKİ & ÖÖİ \\
\hline YD & $0,49 * * *$ & $0,48 * * *$ & $0,36^{* * *}$ & $0,20 * *$ & $0,34 * * *$ & $0,24 * * *$ & $0,27 * * *$ & $0,44 * * *$ \\
\hline PS & - & $0,44^{* * *}$ & $0,36^{* * *}$ & 0,03 & $0,36^{* * *}$ & $0,23^{* * *}$ & $0,23 * * *$ & $0,47 * * *$ \\
\hline Oİ-T & & - & $0,69 * * *$ & $0,58 * * *$ & $0,56^{* * *}$ & $0,50 * * *$ & $0,75 * * *$ & $0,74 * * *$ \\
\hline A & & & - & $0,23 * * *$ & $0,29 * * *$ & $0,24 * * *$ & $0,49 * * *$ & 0,50 *** \\
\hline DD & & & & - & $0,11^{*}$ & $0,32 * * *$ & $0,39 * * *$ & $0,17 * *$ \\
\hline VK & & & & & - & 0,05 & $0,34 * * *$ & $0,37 * * *$ \\
\hline $\mathrm{KP}$ & & & & & & - & $0,16^{* *}$ & 0,30 *** \\
\hline ÖKİ & & & & & & & - & $0,38 * * *$ \\
\hline
\end{tabular}

YD: Yaşam Doyumu; PS: Psikolojik Sağlamlık; Oİ-T: Okul İklimi Toplam; A: Adalet; DD: Düzen

Disiplin; VK: Veli Katılımı; KP: Kaynakların Paylaşımı; ÖKİ: Öğrencilerin Kişilerarası İlişkileri; ÖÖİ: Öğretmen-Öğrenci İlişskileri

$* p<0,05, * * p<0,01, * * * p<0,001$

Elde edilen korelasyon katsayıları, öğrencilerin yaşam doyumu puanları ile psikolojik sağlamlık puanları arasında pozitif yönde ve orta düzeyde anlamlı ilişkiler olduğunu $(r=0,485, \mathrm{p}<0,001)$ göstermektedir. Benzer şekilde öğrencilerin yaşam doyumu puanları ile okul iklimi toplam puanları arasında da pozitif yönde ve orta düzeyde anlamlı ilişkiler olduğu bulunmuştur $(r=0,48, p<0,001)$. Yaşam doyumu puanları ile okul iklimi ölçeğinin adalet alt ölçeği, veli katılımı alt ölçeği ve öğrenci-öğretmen ilişkileri alt ölçek puanları arasında pozitif yönde anlamı ilişkiler bulunurken (sırasıyla $\mathrm{r}=0,36, \mathrm{r}=0,34, \mathrm{r}=0,44, \mathrm{p}<0,001$ ), yaşam doyumu puanları ile okul iklimi ölçeğinin kaynakların paylaşımı ve öğrencilerin kişilerarası ilişkileri ölçekleri arasında $\mathrm{p}<0,001$ anlamlılık düzeyinde pozitif yönde ve düşük düzeyde anlamlı ilişkiler (sırasıyla $\mathrm{r}=0,24$, $\mathrm{r}=0,27)$, düzen ve disiplin alt ölçeği ile $\mathrm{p}<0,01$ düzeyinde pozitif yönde anlamlı ilişkiler $(\mathrm{r}=0,20)$ bulunmuştur.

Ortaokul öğrencilerinin psikolojik sağlamlık puanları ile okul iklimi toplam puanlarının onların yaşam doyumu puanlarının anlamı birer yordayıcısı olup olmadığına karar vermek amacıyla çoklu regresyon analizi (stepwise yöntemi) yapılmıştır. Bunun için ilk basamakta psikolojik sağlamlık ölçeği yaşam doyumunun olası yordayıcısı olarak analize dahil edilmiş, ikinci basamakta ise okul iklimi toplam puanları bir diğer olası yordayıcı değişken olarak analize alınmıştır. Regresyon analizi sonuçları Tablo 3'de verilmiştir.

Tablo 3. Psikolojik Sağlamlık ve Okul İkliminin Yaşam Doyumunu Yordama Gücüne İlişkin Katsayılar

\begin{tabular}{lcccc}
\hline & $\mathrm{B}$ & Standart Hata & $\beta$ & $t$ \\
\hline Sabit & $-2,405$ & 3,336 & & $-0,721$ \\
Psikolojik Sağlamlık & 0,368 & 0,063 & 0,338 & $5,842^{* * *}$ \\
Okul İklimi-Toplam & 0,213 & 0,037 & 0,336 & $5,816^{* * *}$ \\
$\mathrm{R}=0,57, \mathrm{R}^{2}=0,33$, Ayarlanmış $\mathrm{R}^{2}=0,32$ & & & \\
\hline
\end{tabular}


Yordayıc1: Psikolojik Sağlamlık, Okul İklimi

Yordanan: Yaşam Doyumu

$* * * p<0,001$

Tablo 3'de görüldüğü üzere, regresyon analizine dahil edilen her iki yordayıcı değişken olan psikolojik sağlamlık ve okul ikliminin, ortaokul öğrencilerinin yaşam doyumu düzeylerinin anlamlı birer yordayıcısı olduğu bulunmuştur. Her iki değişken birlikte ortaokul öğrencilerinin yaşam doyumu puanlarındaki varyansın \%33'ünü açıklamaktadır. Bu sonuç, psikolojik sağlamlık ve okul iklimiyle yaşam doyumunun \%33’lük bölümünün ortak olduğunu göstermektedir.

\section{Tartışma}

$\mathrm{Bu}$ çalışmanın amacı ortaokul öğrencilerinde psikolojik sağlamlığın ve okul ikliminin yaşam doyumunun anlamlı yordayıcıları olup olmadığını incelemekti. Araştırmadan elde edilen sonuçlar, her iki değişkenin de öğrencilerin yaşam doyumlarının anlamlı birer yordayıcısı olduğunu göstermiştir. Psikolojik sağlamlık ve okul iklimi birlikte öğrencilerin yaşam doyumu puanlarındaki varyansın yaklaşık olarak \%33'ünü açıklamaktadır. İki değişkenin yaşam doyumu üzerindeki etkisinin yaklaşık olarak aynı olduğu görülmüştür. Yapılan önceki ampirik çalışmalar da, çocuk ve ergenlerde yaşam doyumunun hem kişisel faktörler hem de çevresel faktörlerce anlamlı olarak yordandığını göstermektedir (Huebner, Suldo, Smith ve McKnight, 2004).

Araştırmadan elde edilen veriler psikolojik sağlamlık ile öğrenci yaşam doyumu arasındaki ilişkilere işaret eden önceki araştırmaları destekler niteliktedir (Abolghasemi ve Varaniyab, 2010; Baltacı ve Karataş, 2015; Youngblom, Houlihan ve Nolan, 2014). Psikolojik sağlamlığı yüksek olan çocuklar, tipik olarak yüksek benlik saygısına, problem çözme becerilerine, içsel denetim odağına ve sağlıklı kişilerarası iletişim biçimlerine sahip, iyimser, başarılı ve amaç yönelimli çocuklar olarak tanımlanırlar (Rutter, 1987). Söz konusu özellikler, çocuk ve ergenlerin yaşamlarından memnuniyet duymalarına katkıda bulunan özellikler olarak değerlendirilebilir. Mevcut çalışmadan elde edilen bulgular da psikolojik sağlamlığı yüksek olan ortaokul öğrencilerinin yaşamlarından daha fazla memnuniyet duyma eğiliminde olduklarını göstermektedir.

Araştırmadan elde edilen bir diğer bulgu, okul ikliminin yaşam doyumunun anlamlı bir yordayıcısı olmasıdır. Ortaokul öğrencilerinde okul iklimi ile ilgili çalışmalar sınırlıdır. Diğer yandan mevcut bulgular, okul ikliminin öğrencilerin psikolojik sağlı̆̆ üzerinde etkili olduğunu bildiren önceki çalışmaları desteklemektedir (Bugay ve ark., 2015; Cohen ve ark., 2009; Shochet, Dadds, Ham ve Montague, 2006). Ortaokul öğrencilerinin deneyimledikleri negatif olaylar azaldıkça onların yaşam kalitelerine ilişkin algıları yükselmektedir (Ash and Huebner, 2001). Okul ortamı, öğrencilerin zamanlarının önemli bir kısmını geçirdikleri yerler olarak yaşamlarında önemli bir yere sahiptir (Theron, 2016). Bu sebeple, öğrencilerin yaşam doyumunu etkileyen çevresel faktörler bağlamında öğretmen-öğrenci ilişkileri ve akran ilişkilerini içine alan okul ikliminin incelenmesi önem taşımaktadır. Olumlu bir okul iklimi, hem kişisel gelişim hem de akademik başarı için zenginleştirici bir ortam sunmaktadır (Marshall, 2004). Bunun yanında olumlu bir okul ikliminin öğrenciler ve okul çalışanları için olumlu eğitimsel ve psikolojik sonuçları beraberinde getirirken, 
olumsuz bir okul ikliminin öğrenme ve gelişimi önemli ölçüde engelleyebileceği bulunmuştur (Johnson \& Johnson, 1993). Bu araştırmanın sonuçları da ilgili alanyazına paralel olarak okul ikliminin yaşam doyumunun anlamlı bir yordayıcısı olduğunu göstermiştir. Okul ikliminin alt boyutları ile yaşam doyumu arasındaki korelasyon değerleri incelendiğinde ise, okul iklimi ölçeğinin öğretmen-öğrenci ilişkileri alt boyutunun diğer alt boyutlara kıyasla yaşam doyumu ile en güçlü korelasyon değerine sahip olduğu görülmektedir. Liebenberg ve arkadaşları (2016), farklı ülkelerde ve sosyo-ekonomik açıdan riskli bölgelerde öğrenim gören ve yaşları 11 ile 19 arasında değişen toplam 2387 okula devam eden büyük bir öğrenci örneklemiyle yürüttükleri çalışmalarında, öğretmenlerin öğrencilerle kurdukları ilişkiler ve okul ortamlarının ailesel ve toplumsal risklerle karşı karşıya olan çocuk ve ergenlerde olumlu bir farklılık yaratma potansiyellerini vurgulamaktadırlar. Aynı araştırmadan elde edilen sonuçlara göre, öğrencilerin öğretmenleriyle kurdukları ilişkilerin niteliği onların psikolojik sağlamlıkları üzerinde anlamlı ve güçlü bir etkiye sahiptir.

Mevcut araştırma, ortaokul öğrencilerinde yaşam doyumu ile psikolojik sağlamlık ve okul iklimi arasındaki ilişkilere dair önemli bulgular ortaya koymakla birlikte bazı sınırlılıkları vardır. Bunlardan ilki çalışmadan elde edilen verilerin kendini-anlatma tekniklerinden elde edilen verilerden oluşmasıdır. Dolayısıyla elde edilen sonuçlar, kendini-anlatma tekniklerine özgü kişisel yanlılık ve sosyal kabul hatası gibi sınırlılıkları barındırmaktadır. İkincisi, bu çalışma kesitsel bir çalışmadır ve buna bağlı olarak psikolojik sağlamlık ve okul ikliminin yaşam doyumu üzerindeki etkileri aynı katılımcı grubundan eş zamanlı olarak elde edilen verilerle sınırlıdır. İleride yapılacak boylamsal çalışmalar bu ilişkileri incelemek bakımından önemli katkılar getirebilir. Son olarak araştırmadan elde edilen veriler İzmir metropol ilçelerinde bulunan iki farklı devlet ortaokuluna devam eden öğrencilerden toplanan bilgilerle sınırlıdır. Daha geniş ve kültürel açıdan çeşitlilik gösteren öğrencilerle yapılacak çalışmalar konu ile ilgili mevcut sonuçları desteklemek bakımından yararlı olabilir.

\section{Sonuç ve Öneriler}

Öğrencilerin yaşam doyumlarının geliştirilmesi farklı gerekçelerle kritik önem taşıyan bir konudur. Bunlardan ilki, yaşam doyumundaki artışın psikolojik sağlı yanında akademik gelişimle ilişkili olmasıdır. Akademik başarı gerek eğitimcilerin gerekse ebeveynlerin geleneksel olarak çocuklarla ilgili en önemli beklentileri arasındadır. Öğrencilerin yaşam doyumlarını arttırmaya yönelik çalışmaların onların aynı zamanda akademik gelişimlerini de destekleyici olması önemlidir. Öğrencilerin yaşam doyumlarının geliştirilmesini önemli kılan bir diğer gerekçe, onların ergenlik ve izleyen gelişimsel süreçlerinde karşılaştıkları zorlukların üstesinden daha başarılı olarak gelmelerini sağlayarak uzun vadede kişisel gelişimlerini destekleyici olmasıdır.

Araştırmadan elde edilen bulgulardan hareketle, öğrencilerin psikolojik sağlamlıklarını arttırmaya ve olumlu bir okul iklimini oluşturmaya yönelik çalışmaların onların yaşam doyumlarını geliştirmeye katkı vereceğini söylemek mümkündür. Okul ikliminin geliştirilmesine yönelik çalışmalar kapsamında öğretmen-öğrenci 
ilişkilerinin geliştirilmesine yönelik çalışmalara ağırlık verilmesi, mevcut çalışmadan çıkarılabilecek sonuçlar arasındadır.

Okul-temelli psikolojik sağlamlığı desteklemeye yönelik hizmetler formal ya da informal olarak verilebilmektedir. Psikolojik sağlamlığı geliştirmeye yönelik yapılandırılmış müdahale programları formal; yapıcı öğretmen-öğrenci ilişkileri kurmak ya da olumlu bir okul iklimi oluşturmak ise informal destekler olarak değerlendirilebilir (Theron, 2016). Okul ortamlarında her iki yaklaşıma dayalı çalışmaların tasarlanması ve uygulanması öğrencilerin psikolojik sağlamlıklarını geliştirmek bakımından etkili olabilir.

Okul psikolojik danışmanları bu araştırmanın sonuçlarından yararlanabilirler. Onlar, öğretmenler, okul yöneticileri ve velilerle birlikte çalışarak bir taraftan öğrencilerin psikolojik sağlamlıklarını geliştirmeye yönelik olarak kişisel ve kişilerarası becerilerinin geliştirilmesini hedef alan programlar uygulayabilirler; diğer yandan öğretmen-öğrenci ilişkilerini geliştirmek başta olmak üzere okulda olumlu bir öğrenme atmosferinin oluşturulmasına yönelik çalışmalara önderlik yapabilirler. Okul psikolojik danışmanlarının okul ortamlarında öğrencilere yönelik çalışmalar yanında, konsültasyon çalışmaları aracılığıyla öğretmenler ve okul yöneticileri ile yapacaklara çalışmalara gereksinim olduğu anlaşılmaktadır. Bu çalışmalar kapsamında öğretmenlerin öğrencileri ile daha nitelikli, ilgili ve destekleyici ilişkiler geliştirmelerine ve okul yöneticilerinin öğrencilerin olumlu gelişimlerini destekleyen güvenli okul atmosferleri oluşturmalarına odaklanmanın onların hem psikolojik iyi oluşlarını hem de akademik gelişimlerini desteklemek bakamından çok önemli bir yere sahip olduğu vurgulanmalıdır.

\section{Kaynaklar}

Abolghasemi , A. ve Varaniyab , S.T. (2010). Resilience and perceived stress: predictors of life satisfaction in the students of success and failure. Procedia - Social and Behavioral Sciences, 5, 748-752.

Adelman, H. S., Taylor, L., \& Nelson. (1989). Minors dissatisfaction with their life circumstances. Child Psychiatry \& Human Development, 20(2), 135-147.

Alvidrez, J., \& Weinstein, R. S. (1993). The nature of "schooling" in school transitions: A critical reexamination. Prevention in Human Services, 10, 7-26.

Arslan, G. (2015). Çocuk ve Genç Psikolojik Sağlamlık Ölçeği’nin (ÇGPSÖ-12) psikometrik özellikleri: Geçerlilik ve güvenirlik çalışması. Ege Ĕ̈itim Dergisi, 16, 1: 1-12.

Ash, C., \& Huebner, E. S. (2001). Environmental events and life satisfaction reports of adolescents: A test of cognitive mediation. School Psychology International, 22, 320 - 336.

Atik, G. ve Yerin Güneri, O. (2016). Ortaokul öğrencileri için okul iklimi ölçeği: Türkçe formu'nun geçerlik ve güvenirlik çalışması. Illkögretim Online, 15(1), 91-103.

Bugay, A., Aşkar, P., Tuna, M.E., Çelik Örücü, M. ve Çok, F. (2015). Okul iklimi ölçeği lise formu'nun türkçe psikometrik özellikleri. Illköğretim Online, 14(1), 311- 322.

Cohen, J., McCabe, E. M., Michelli, N. M., \& Pickeral, T. (2009). School climate: Research, policy, practice, and teacher education. Teachers College Record, 111(1), 180-213.

Çivitçi, A. (2009). İlköğretim öğrencilerinde yaşam doyumu: bazı kişisel ve ailesel özelliklerin rolü. Uludă̆ Üniversitesi Eğitim Fakültesi Dergisi, XXII(1), 29-52.

Çokluk, U., Şekercoğlu, G. ve Büyüköztürk, Ş. (2012). Sosyal bilimler için çok değisşkenli istatistik. Pegem Akademi. Ankara. 
Diener, E., \& Diener, M. (1995). Cross-cultural correlates of life satisfaction and self-esteem. Journal of Personality and Social Psychology, 68, 653-663.

Eccles, J. S., Midgley, C., Wigfield, A., Buchanan, C. M., Reuman, D., Flanagan, C., \& MacIver, D. (1993). Development during adolescence: The impact of stage-environment fit on young adolescents' experiences in schools and in families. American Psychologist, 48, 90-101.

Gilman, R., \& Huebner, E. S. (2003). A review of life satisfaction research with children and adolescents. School Psychology Quarterly, 18, 192-205.

Greenspoon, P. J. \& Saklofske, D. H. (2001). Toward an integration of subjective well-being and psychopathology. Social Indicators Research, 54, 81 - 108.

Huebner, E. S., Suldo, S. M., Smith, L. C., \& McKnight, C. G. (2004). Life satisfaction in children and youth: Empirical foundations and implications for school psychologists. Psychology in the Schools, 41(1), 81-93.

Johnson, B. (2008). Teacher-students relationships which promote resilience at school: a micro-level analysis of students' views. British Journal of Guidance \& Counseling, 36(4), 385-398.

Johnson, W. L., \& Johnson, M. (1993). Validity of the quality of school life scale: A primary and secondorder factor analysis. Educational \& Psychological Measurement, 53(1), 145-153.

Karaırmak, Ö. (2006). Psikolojik sağlamlık, risk faktörleri ve koruyucu faktörler. Türk Psikolojik Danışma ve Rehberlik Dergisi, 26, 129-142.

Kuperminc, G. P., Leadbeater, B. J., \& Blatt, S. J. (2001). School social climate and individual differences in vulnerability to psychopathology among middle school students. Journal of School Psychology, $39,(2), 141-159$.

Liebenberg, L., Ungar, M. ve Van de Vijver, F. R. R. (2012). Validation of the Child and Youth Resilience Measure-28 (CYRM-28) among canadian youth with complex needs. Research on Social Work Practice, 22(2), 219-226.

Liebenberg, L., ve ark. (2016). Bolstering resilience through teacher-student interaction: Lessons for school psychologists. School Psychology International, 37(2), 140-154.

Marshall, M. L. (2004). Examining school climate: defining factors and educational influences [white paper, electronic version]. Retrieved (month, date, year) from Georgia State University Center for School Safety, School Climate and Classroom Management website: http://education.gsu.edu/schoolsafety/

Proctor, C. L., Linley, P.A. ve Maltby, J. (2009). Youth life satisfaction: A Review of the literature. Journal of Happiness Studies, 10, 583-630.

Rutter, M. (1987) Psychosocial resilience and protective mechanisms. American Journal of Orthopsychiatry, $57,316-31$.

Shochet, I. M., Dadds, M. R., Ham, D., \& Montague, R. (2006). School connectedness is an underemphasized parameter in adolescent mental health: Results of a community prediction study. Journal of Clinical Child \& Adolescent Psychology, 35, 170-179.

Seidman, E., Allen, L., Aber, J. L., Mitchell, C., \& Feinman, J. (1994). The impact of school transitions in early adolescence on the self-system and perceived social context of poor urban youth. Child Development, 65, 507-522.

Seligson, J. L., Huebner, E. S., \& Valois, R. F. (2003). Preliminary validation of the brief multidimensional students' life satisfaction scale (BMSLSS). Social Indicators Research, 61, 121-145.

Siyez, D. M. ve Kaya, A. (2008). Validity and reliability of the Brief Multidimensional Students' Life Satisfaction Scale with Turkish children. Journal of Psychoeducational Assessment, 26, 139-147.

Theron, L. C. (2016). The everyday ways that school ecologies facilitate resilience: Implications for school psychologists. School Psychology International, 37(2) 87-103.

Werner, E. E. (1995). Resilience in development. Current Directions in Psychological Science, 4, 81-84. 
Youngblom, R., Houlihan, D. ve Nolan, J. (2014). An Assessment of resiliency and life satisfaction in high school-aged students in Belize. International Journal of Psychological Studies, 6(4), 115-122.

\section{Extended Abstract}

Introduction

Life satisfaction is one of the major constructs of positive psychology. Life satisfaction is a cognitive component of subjective well-being. It refers to an individual's evaluation of his own life. People who perceive their lives as favorable tend to experience higher levels of life satisfaction. Research findings show that life satisfaction is significantly related to both positive and negative outcomes of human life. While higher levels of life satisfaction is correlated to adaptive constructs such as psychological well-being, hope and self-esteem, lower levels of life satisfaction is correlated to psychological problems such as depression and anxiety.

Life satisfaction studies mainly focus on late adolescent and adult populations. Recently, researchers have showed interest in life satisfaction among children and early adolescents. The findings of these studies have indicated that life satisfaction is major indicator of psychological well-being of children. Life satisfaction of children is associated to both personal growth and academic achievement.

\section{Purpose}

The aim of this study is to determine whether resilience and school climate predict overall life satisfaction in a sample of middle school students. Middle school students experience rapid changes in physical, emotional, and interpersonal development. These changes may affect the well-being of all students. In this period, individual differences among children and their school environments are major determinants of their wellbeing. In the current study we address two factors as potancial determinants of middle school students' life satisfaction: Resilience as an individual characteristic and school climate as an environmental factor.

Resilience is the ability to cope with negative events, difficult situations and challenges and to return to similar level of emotional well-being. Being resilient helps to promote psychological well-being. Previous reserach on resilience and life satisfaction among children and adolescents have revealed that resilience is a significant predictor of life satisfaction.

School climate is another variable which is associated with life satisfaction of children. School climate is an extensive and comlex construct. It includes multiple elements such as interactions between adults and students and environmental factors. Previous research findings regarding school climate have revealed that school climate is associated with behavioral and emotional problems of students. School climate can also affect life satisfaction of children.

Method and Participants

The present study specifically focus on predictive roles of resilience and overall school climate in life satisfaction levels of middle school students. A total of 254 middle school students (127 girls and 127 boys) 
aged 10 to 15 years participated in the study. The Brief Multidimensional Students' Life Satisfaction Scale, The Child and Youth Resilience Scale and middle school student version of School Climate Survey were used to gather data. Descriptive statistics, Pearson correlation analysis and stepwise regression analysis were used to analyze the data.

Results

Means, standard deviations, the range, skewness and kurtosis for the research scale scores were calculated. The descriptive analysis showed that all scales had good scores of symmetry and kurtosis. In order to examine correlations between life satisfaction and resilience and school climate total scale and subscales, Pearson correlations were calculated. Life satisfaction was found to be significantly and positively correlated with resilence $(r=.48, \mathrm{p}<.001)$. Life satisfaction was also found to be significantly and positively correlated with Fairness $(r=.36, p<.001)$, with Order and Discipline $(r=.20, p<.01)$, with Parent Involvement $(r=$ $.36, \mathrm{p}<.001)$, with Sharing of Resources $(\mathrm{r}=.34, \mathrm{p}<.001)$, with Student Interpersonal Relations $(\mathrm{r}=.27, \mathrm{p}$ $<.001)$, with Student-Teacher Relations $(\mathrm{r}=.44, \mathrm{p}<.001)$ and with School Climate total score $(\mathrm{r}=.48, \mathrm{p}<$ .001). In order to determine predictive role of resilience and overall school climate in life satisfaction, stepwise regression analysis was used. The results revealed that resilience and school climate significantly and positively predicted life satisfaction scores in middle school students. Resilience and school climate, taken together, accounted for significant variation in life satisfaction scores, $\mathrm{R}^{2}=33, \mathrm{p}<.001$.

\section{Discussion}

The findings are consistent with previous findings indicating associations between life satisfaction and resilience. In the current study we found that children with higher resiliency are more likely to satisfy their life. Similarly, previous research on resilience and life satisfaction in children and adolescents revealed that children with higher resiliency are less likely to suffer from social and psychological health problems and more likely to have higher levels of life satisfaction. Additionally, resilience is associated with several individual competence and skills such as social skills, problem solving skills, higher levels of self-esteem and higher levels of hope. Therefore being resilient may affect life satisfaction of all children.

The findings are also consistent with previous research regarding school climate correlates of life satisfaction. Psychological well-being of children depends upon both internal and external factors. School climate is one of the major environmental factors which affect life satisfaction of children. School climate includes children's relationships with their peers and teachers and physical environmental factors. Previous studies showed that the quality of children's school environments predicts their life satisfaction.

Previous research revealed that multiple factors including individual characteristics and environmental factors are involved in well-being of children and adolescents. The current study clearly demonstated the predictive role of resilience and school climate in life satisfaction among middle school students. 


\section{Conclusion}

School counselors would benefit from the findings of this research in order to promote the students' wellbeing. School-aged children spend a large amount of time in school settings. Therefore school counselors need to take strenght-based approaches that aim to promote positive development of all children. These approaches can improve both life satisfaction and academic achievement of children. School principals may also take responsibility for enhancing life satisfaction of children. They need to build positive school environmets that promote well-being and resilience of all children. The importance of teacher support in promoting all children's well-being must be underscored. To improve school climate, school principals and teachers should treat students fairly, supportive and and with respect. 